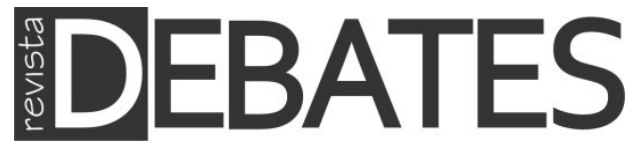

\title{
Há um desenho institucional favorável à independência judiciária? Um panorama das constituições vigentes na América Latina
}

\author{
Is there an institutional structure conducive to judicial \\ independence? An overview of ruling constitutions in Latin America
}

\section{Rebecca Magalhães Ernani Carvalho}

\section{Resumo}

O que determina o caráter da revisão judicial da forma como ela funciona nas novas democracias? Fatores institucionais parecem impactar a independência e poder das cortes e, portanto, frequentemente são utilizados para explicar seu comportamento. Mecanismos como composição das cortes, jurisdição, seleção dos membros e tempo do mandato comumente figuram detalhadamente nos textos constitucionais, sinalizando que a autonomia das cortes é tradicionalmente um ideal desejável pelos constituintes. Neste artigo pretendemos analisar como certas características podem ser determinantes na promoção da independência judicial e, finalmente, verificar quais se encontram presentes nas cortes constitucionais na América Latina.

\section{Palavras-chave}

Independência Judicial; América Latina; Cortes Constitucionais.

\begin{abstract}
What determines the nature of judicial review and the way it operates in the new democracies? Institutional factors seem to impact the independence and power of courts and therefore are often used to explain their behavior. Mechanisms such as composition of the courts, jurisdiction, and selection of members of the term commonly listed in detail in constitutional texts, signaling that the autonomy of the courts is traditionally a desirable ideal for constituents. This article aims to analyze how certain characteristics may be crucial in promoting judicial independence and ultimately determine which are present in the constitutional courts in Latin America.
\end{abstract}

\section{Keywords}

Judicial Independence; Latin America; Constitutional Courts. 


\section{Introdução}

A construção das regras constitucionais reflete em grande medida o ambiente contratual das diversas forças políticas que amparam e legitimam o processo político. A busca das motivações, de como se deu essa construção, é essencial para o entendimento de seus desdobramentos.

Neste artigo exploramos um pequeno segmento desta busca, com foco na América Latina, mais especificamente, nas configurações disponíveis nos textos constitucionais vigentes de 19 casos selecionados (Argentina, Bolívia, Brasil, Chile, Colômbia, Costa Rica, El Salvador, Equador, Guatemala, Haiti, Honduras, México, Nicarágua, Panamá, Paraguai, Peru, República Dominicana, Uruguai e Venezuela). $\mathrm{O}$ objetivo consiste em verificar quais constituiçôes apresentam características mais favoráveis à independência do judiciário, de acordo com modelos propostos pela revisão de literatura apresentada.

A partir da ferramenta de busca textual, todas as constituições foram analisadas, no que diz respeito aos dispositivos acerca de suas cortes constitucionais, para então se dar início a um estudo comparativo e sistemático entre cada uma delas. Fatores institucionais que parecem impactar a independência e poder das cortes constitucionais, frequentemente, são utilizados para explicar seu comportamento e, partindo dessa premissa, mecanismos importantes como composição das cortes, jurisdição, seleção dos membros e tempo do mandato comumente figuram detalhadamente nos textos constitucionais ${ }^{1}$.

A independência das cortes é certamente um ideal desejável, tendo em vista a necessidade da maior imparcialidade possível por parte de um julgador e, por essa razão, as ferramentas institucionais buscam intervir no sentido de manter os juízes isolados de interferências externas e aumentar sua autonomia. Portanto, a independência judicial, nesse sentido, pode ser considerada como uma condição necessária, embora não suficiente, para a realização do rule of law.

Os estudos dessa linha de pesquisa comumente separam a independência judicial em duas dimensóes: de jure e de facto, sendo a primeira correspondente às premissas constitucionais ou legais que regulam garantias de independência do judiciário e a segunda, tocante à independência factualmente obtida pelas cortes em determinado cenário político (HAYO e VOIGT, 2007; RÍOS-FIGUEROA, 2007).

$\mathrm{O}$ que determina a independência judicial e como opera nas novas democracias? Este artigo parte da hipótese de que um alto grau de independência de

\footnotetext{
1 Embora em alguns casos, como a Bolívia ou Costa Rica, as disposiçôes gerais relativas ao funcionamento e composição da corte constitucional se encontrem em lei orgânica específica.
} 
jure é a forma mais eficiente de incrementar a de facto. Para Ginsburg (2003, p. 23) a configuração das cortes constitucionais reflete em grande parte as escolhas daqueles que as projetam: "as barganhas políticas envolvidas no início do regime democrático e incorporadas no texto constitucional vão certamente incluir algumas disposições para revisão judicial”.

Por vários motivos a América Latina se torna um laboratório fértil para linhas de pesquisas relacionadas a mudanças institucionais, uma vez que a região é marcada por períodos de oscilação entre ditadura e democracia, com constituiçôes democráticas recentes e mudanças constantes em seus textos.

A literatura examinada demonstra que há poucos estudos comparativos com maior amplitude, sendo em sua maioria resumidos a poucos países, o que parece sinalizar que há uma parte relativamente inexplorada da América Latina. Percebemos que as abordagens, métodos e pontos de vista dificultam o trabalho de encontrar consenso em muitos assuntos, muitos autores afirmam que é um desafio obter dados confiáveis. Algumas pesquisas que podem ser consideradas clássicas foram revisitadas e representam o que foi obtido a partir de tentativas de medir graus de independência em perspectiva comparada, apesar da complexidade que a investigação possui.

Quanto às variáveis apresentadas pela literatura disponível, comumente orbitam entre forma de nomeação dos juízes das cortes superiores, duração do mandato, quantidade de membros das cortes, possibilidade de recondução, procedimento de destituição, salário e formas de redução ou aumento, acessibilidade, temática dos casos admitidos e alcance das decisões (VERNER, 1984; HAYO e VOIGT, 2007; ELKINS, GINSBURG e MELTON, 2009; RÍOS-FIGUEROA, 2007). Este trabalho enfatizou as maiores dimensões objetivas em que os sistemas variam: o acesso às cortes, o efeito e a modulação temporal das decisões, o tamanho das cortes e a duraçáo do mandato.

O acesso é um elemento que reflete muito a posição das forças políticas no sistema constitucional, pois quando amplo, descentraliza o poder de trazer questóes a um maior número de atores. Em regra um partido dominante irá preferir mantê-lo restrito; em um contexto de fragmentação partidária, buscar-se-á sua ampliação (GINSBURG, 2003). Portanto, quanto maior o número de instituiçôes com poder de veto, maior probabilidade de aumento do poder do judiciário.

Os efeitos e limites temporais de aplicabilidade das decisões judiciais relacionam-se diretamente com o impacto que os magistrados esperam de seu poder decisório, ainda que contrário aos interesses de outros membros do governo (HAYO e VOIGT, 2007). Esmiuçados no item "Tipos de Controle: Difuso e/ou Concentrado e Acesso às Cortes", os efeitos derivam do conceito de stare decisis, 
expressão que significa "ficar com as coisas decididas". Tradicionalmente os sistemas de common law concediam um forte peso à jurisprudência, vinculando decisóes futuras. Conforme esta característica aproxima a função do judiciário de quaselegislar, quanto mais amplos os efeitos, maior tenderá a ser a independência do judiciário.

Por fim, o tamanho das cortes e duração do mandato correlacionam-se não apenas com a interferência dos atores que os nomeiam, mas também com o perfil dos magistrados - mais ou menos favorável ao empoderamento das cortes.

Frise-se que, no entanto, este trabalho náo pretende verificar se realmente os efeitos institucionais são obtidos, pois é um processo que envolve muitas complexidades; como as instituiçóes não funcionam em um vácuo, muitas vezes o seu impacto é mediado pelos contextos políticos, sociais e ideológicos.

Exatamente por esse motivo, parte considerável das publicações encontradas na revisão da literatura opta por utilizar como forma de mensuração pesquisas de opiniáo, com o objetivo de medir como o judiciário é visto pela sociedade, se os cidadáos o consideram independente, eficiente, corrupto ou acessível. Entretanto, um bom começo para avaliar se as instituições produzem impacto é especificar claramente o quadro institucional e os incentivos lançados aos indivíduos.

\section{Emendas Relacionadas ao Judiciário}

Pozas-Loyo e Ríos-Figueroa (2010) colheram dados acerca das emendas às constituições latino-americanas referentes ao judiciário, entre 1945 e 2002. O objetivo dos autores era testar a hipótese de que processos multilaterais de construção constitucional (envolvendo um maior número de atores políticos) apresentavam maiores avanços aos anseios democráticos do constitucionalismo do que processos unilaterais. Muitas conclusóes dessa pesquisa são de grande utilidade para verificar se há novos desenhos favoráveis à independência do judiciário e quais dos casos aparentam ter se aproximado mais significativamente. 
Quadro 1 - Constituiçôes e Emendas ao Judiciário na América Latina (1945-2013)

\begin{tabular}{|c|c|}
\hline Unilateral & Multilateral \\
\hline Argentina - 1949 & Argentina - 1957* e 1994 \\
\hline Bolívia - 1947 e 1967 & Bolívia - 1995*, 2002 e 2009 \\
\hline Brasil - 1967 & Brasil - 1947, 1988, 1993*, 1998* e $2004^{*}$ \\
\hline Chile - 1980 & Chile $-1970^{*}, 1997^{*}$ e $2005^{*}$ \\
\hline Costa Rica - 1949 & Colômbia- 1957*, 1968*, 1979*, 1991, 1997* e 2001* \\
\hline República Dominicana - 1966 & Costa Rica - 1989*, 1993* e 2003* \\
\hline Equador - 1946 e 1967 & República Dominicana - $1994^{*}$ \\
\hline El Salvador - 1950 e 1963 & Equador - 1945, 1978, 1984*, 1993*, 1996* e 1998 \\
\hline Guatemala - 1956 & El Salvador - 1983, 1991* e 2012* \\
\hline $\begin{array}{c}\text { Haiti - 1950, } 1957,1964,1983 \mathrm{e} \\
1987^{*}\end{array}$ & Guatemala - 1945, 1965 e 1985 \\
\hline Honduras - 1957 e 1965 & Haiti - 2012* \\
\hline $\begin{array}{c}\text { Nicarágua - } 1948,1950,1974 \text { e } \\
1987\end{array}$ & Honduras - 1982, 2000* e $2003^{*}$ \\
\hline Panamá - 1946, 1972 e 1983* & México - 1994* e 1999* \\
\hline Paraguai - 1967 e 1992 & Nicarágua $-1995^{*}$ e $2000^{*}$ \\
\hline Peru - 1993 e $1995^{*}$ & Peru - 1979 \\
\hline \multirow[t]{2}{*}{ Venezuela - 1947, 1953 e 1999} & Uruguai - 1952 e 1967 \\
\hline & Venezuela - 1961 \\
\hline
\end{tabular}

* Emendas constitucionais que afetam instituições relacionadas ao judiciário.

Fonte: Pozas-Loyo e Ríos-Figueroa (2010).

Atualizamos o quadro sugerido, para alcançar até 2013, incluindo nos achados da pesquisa citada casos que apresentaram reformas pertinentes às cortes constitucionais desde 2005 até 2013: Bolívia (2009), Colômbia (2009), El Salvador (2006), Haiti (2012), México (2011), República Dominicana (2010) e Venezuela (2009). Adicionamos o Haiti que não figurava na pesquisa na qual nos embasamos.

Nosso critério para interpretar como unilateral e multilateral foi diferente do original, que tinha como base a porcentagem de representantes dos partidos ou grupos sociais presentes no quórum necessário à aprovação da emenda. Em nosso 
estudo, com fins exploratórios, consideramos apenas a presença ou ausência de um presidencialismo autoritário e a repercussáo internacional da emenda, como o emblemático caso da reeleição de Evo Morales, em 2009, e o mandato vitalício de Duvalier no Haiti, em 1964.

É possível observar que significativa parte dos casos selecionados apresentaram emendas constitucionais voltadas ao judiciário entre o período de 1990 e 2000, entretanto não necessariamente ocorridas em um ambiente democrático favorável. Ainda assim, destacamos algumas reformas interessantes, como a instituição da Corte Constitucional na República Dominicana em 2010, que até então não existia. Há claros sinais de que houve iniciativas para mudanças no judiciário, consolidadas nas constituições atuais. Com base nesses achados o próximo passo é naturalmente investigar sobre em que pontos as reformas têm sido mais significativas.

\section{Método de seleção dos magistrados e tamanho das cortes}

Geralmente, os constituintes definem o número de membros da corte. $\mathrm{O}$ maior tradte-off em determiná-lo é entre rapidez da decisão ou precisão do veredito, pois quanto maior o número de magistrados, menores as chances de se cometer erros. Dessa feita, é possível relacionar cortes menores a mais partidos dominantes, porque, conforme Ginsburg (2003), há menos facções preocupadas com sua representatividade e menor necessidade de manter os juízes divididos e porque, naturalmente, não haveria interesse em aumentar os gastos no orçamento.

Pela análise dos casos selecionados, há grande variação, sendo a média equivalente a 10,36 membros, de acordo com o Quadro 2. Desprezando Costa Rica e Venezuela, pois destoam consideravelmente dos demais casos, teríamos uma média de 8,41 membros, o que quase coincide com o número apontado por Ginsburg (2003) correspondente à média de demais jovens democracias analisadas, qual seja, 8,25 membros.

Destacamos que algumas das cortes não possuem jurisdição apenas constitucional, portanto, acumulam funçôes de realizar o controle de constitucionalidade e atuar como cortes recursais de última instância (como no Brasil). Talvez isso explique em parte a hipertrofia da Costa Rica e da Venezuela, visto que náo parecem corroborar a teoria de que seria um sinal da existência de menos partidos dominantes. Ou seja, a razão para que o tamanho seja maior nesses dois casos específicos deve-se ao fato de que foram aglutinadas o que antes eram duas cortes, uma com a função de atuar como tribunal revisional e outra como corte constitucional. 
Quadro 2-Tamanho das Cortes

\begin{tabular}{|c|c|}
\hline \multicolumn{2}{|c|}{ Quantidade de mebros } \\
\hline 5 & Guatemala \\
\hline 5 & Urugrai \\
\hline 7 & Bolívia \\
\hline 7 & Chile \\
\hline 9 & Argentina \\
\hline 9 & Colombia \\
\hline 9 & Equador \\
\hline 9 & Haiti \\
\hline 9 & Paraguai \\
\hline 9 & Panamá \\
\hline 11 & Brasil \\
\hline 11 & México \\
\hline 13 & Republica Dominicana \\
\hline 15 & Honduras \\
\hline 15 & El Salvador \\
\hline 16 & Peru \\
\hline 16 & Nicarágua \\
\hline 22 & Costa Rica \\
\hline 32 & Venezuela \\
\hline
\end{tabular}

Fonte: Os autores, com base nas constituiçōes.

De fato, um dos poucos consensos encontrados na literatura revisada diz respeito à importância de manter o judiciário livre dos abusos do executivo na América Latina e de exercer sua função de accountability - sem entrarmos no mérito dos riscos de um judiciário hipertrofiado.

Com o objetivo direcionado a minimizar as influências indesejadas em sua imparcialidade, os desenhos constitucionais tendentes a proteger seu isolamento da ingerência de outros atores, em geral envolvem disposiçôes sobre indicação, formas de remoção do cargo e mandato dos magistrados (RÍOS-FIGUEROA, 2009).

Em relação à nomeação dos membros, a independência judicial é um objetivo central da maioria dos sistemas analisados e os sistemas de indicaçáo são vistos como um mecanismo fundamental para atingir esse objetivo. Juízes que são dependentes de alguma forma em relação à pessoa que os nomeia, tornam-se menos propensos a conceber decisões neutras e de alta qualidade. 
Appointments are among the most crucial of design issues. Constitutional designers are unlikely to adopt constitutional review unless they believe it will be carried out by impartial appointees. If designers believe they are likely to lose postconstitutional elections, they will be not in a position to appoint judges. So overly partisan mechanisms are especially unattractive. The normative task is to select an appointment mechanism that will maximize the chances that the judge will interpret the text in accordance with the intentions of constitution writers (GINSBURG, 2003, p. 42) 2

Os sistemas de nomeação dos magistrados geralmente são baseados em indicação por instituiçóes políticas, pelo próprio judiciário, por um conselho de justiça ou por sufrágio. Os métodos de seleção variam dentro dos países, de acordo com os níveis de jurisdição e também variam consideravelmente de um país para outro, sendo mais comum arranjos entre indicações por instituições políticas e pelo próprio judiciário.

Ginsburg (2003) divide as formas de nomeação em três espécies, que não obstante, podem ser combinadas: profissional, cooperativa e representativa. A escolha dos membros com base no critério profissional, geralmente são feitas pelo próprio tribunal, sendo recomendável no sentido de favorecer um perfil mais técnico na nomeação. O critério cooperativo requer que dois ou mais órgãos estejam envolvidos no processo de escolha, sendo comum que o chefe do executivo nomeie e a escolha seja aprovada pelo corpo legislativo. E finalmente, o critério representativo, que utiliza múltiplas autoridades para a escolha.

Ríos-Figueroa (2009) sugere que a forma que proporciona maior garantia é a da indicação por parte do judiciário, pois evita que atores externos possam exercer alguma influência naqueles membros que os nomearam. No entanto, verificamos que nenhum dos casos selecionados utiliza tal critério.

\footnotetext{
${ }^{2}$ As nomeações estão entre os temas mais cruciais do design. Os constituintes não são propensos a adotar a revisão judicial a menos que acreditem que os magistrados serão nomeados de forma imparcial. Se os constituintes acreditam que provavelmente irão perder as próximas eleições, então não estarão na posição que lhes permita indicar os juízes, portanto, mecanismos partidários são particularmente pouco atraentes. A tarefa normativa é escolher um mecanismo de seleçáo que maximize as chances de que o juiz interprete o texto de acordo com as intençóes de seus criadores (tradução dos autores).
} 
Quadro 3 - Nomeação, Jurisdição e Duração do Mandato

\begin{tabular}{|c|c|c|c|c|c|}
\hline $\begin{array}{c}\text { Corte } \\
\text { Constitucional }\end{array}$ & $\begin{array}{l}\text { Jurisdiçáo } \\
\text { Constitucional } \\
\text { é separada do } \\
\text { contencioso? }\end{array}$ & $\begin{array}{l}\text { Autoridades } \\
\text { que designam } \\
\text { os membros }\end{array}$ & $\begin{array}{l}\text { Duraçáo do } \\
\text { mandato }\end{array}$ & $\begin{array}{l}\text { Renovaçáo do } \\
\text { mandato }\end{array}$ & $\begin{array}{c}\text { Qualidades } \\
\text { universitárias ou } \\
\text { profissionais exigidas } \\
\text { dos membros }\end{array}$ \\
\hline Argentina & $\begin{array}{l}\text { Não, Suprema } \\
\text { Corte. }\end{array}$ & $\begin{array}{l}\text { Presidente, com } \\
\text { aprovação de } \\
\text { exposiçáo } \\
\text { pública e } \\
\text { aprovação do } \\
\text { senado. }\end{array}$ & Vitalício & & $\begin{array}{l}6 \text { anos de cidadania } \\
\text { argentina, renda de } 2 \\
\text { mil pesos anuais, } 8 \\
\text { anos de advocacia. }\end{array}$ \\
\hline Bolívia & $\begin{array}{l}\text { Sim, Tribunal } \\
\text { Constitucional } \\
\text { Plurinacional. }\end{array}$ & $\begin{array}{l}\text { Sufrágio } \\
\text { universal. }\end{array}$ & 6 anos & Não & $\begin{array}{l}8 \text { anos de advocacia, } \\
\text { experiência em } \\
\text { Constitucional } \\
\text { Administrativo ou } \\
\text { Direitos Humanos. }\end{array}$ \\
\hline Brasil & $\begin{array}{l}\text { Não, Supremo } \\
\text { Tribunal } \\
\text { Federal também } \\
\text { é recursal. }\end{array}$ & $\begin{array}{l}\text { Presidente, com } \\
\text { aprovação do } \\
\text { senado. }\end{array}$ & Vitalício & & $\begin{array}{l}\text { Notável saber jurídico e } \\
\text { reputação ilibada. }\end{array}$ \\
\hline Chile & $\begin{array}{l}\text { Sim, Tribunal } \\
\text { Constitucional } \\
\text { Plurinacional. }\end{array}$ & $\begin{array}{c}\text { - } 3 \text { juízes } \\
\text { (Supremo) } \\
\text { - } 1 \text { advogado } \\
\text { (Presidente) } \\
\text { - } 2 \text { advogados } \\
\text { (Conselho de } \\
\text { Segurança) - } 1 \\
\text { advogado } \\
\text { (Senado) }\end{array}$ & 8 anos & Sim & $\begin{array}{l}15 \text { anos de título e } \\
\text { destaque na atividade } \\
\text { profissional, } \\
\text { universitária ou } \\
\text { pública. }\end{array}$ \\
\hline Colombia & $\begin{array}{c}\text { Sim, Corte } \\
\text { Constituciona }\end{array}$ & $\begin{array}{l}-3 \text { (Supremo) } \\
-3 \text { (Presidente) } \\
-3 \text { (Senado) }\end{array}$ & 8 anos & Não & $\begin{array}{l}\text { Colombiano nato e } \\
\text { advogado, } 10 \text { anos de } \\
\text { experiencia, náo ter } \\
\text { sido condenado a } \\
\text { sentença privativa de } \\
\text { liberdade. }\end{array}$ \\
\hline Costa Rica & $\begin{array}{l}\text { Não, Suprema } \\
\text { Corte de Justiça. }\end{array}$ & $\begin{array}{l}\text { Assembleia } \\
\text { Legislativa. }\end{array}$ & 8 anos & Sim & $\begin{array}{l}10 \text { anos de advocacia } \\
\text { ou funçáo jurídica } \\
\text { pública por } 5 \text { anos. }\end{array}$ \\
\hline El Salvador & $\begin{array}{l}\text { Não, Suprema } \\
\text { Corte. }\end{array}$ & $\begin{array}{l}\text { Conselho } \\
\text { Nacional de } \\
\text { Justiça e } \\
\text { Assembleia } \\
\text { Legislativa }\end{array}$ & 9 anos & Não & 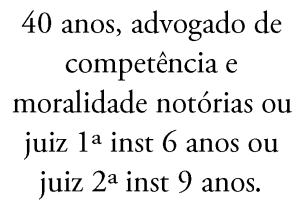 \\
\hline
\end{tabular}




\begin{tabular}{|c|c|c|c|c|c|}
\hline Equador & $\begin{array}{c}\text { Sim, Corte } \\
\text { Constitucional. }\end{array}$ & $\begin{array}{c}\text { Senado aprova } \\
\text { indicados por } \\
\text { Presidente, } \\
\text { Suprema Corte } \\
\text { e outros oficiais }\end{array}$ & 9 anos & Não & $\begin{array}{l}10 \text { anos de advocacia } \\
\text { ou docência; ter } \\
\text { terceiro nível em } \\
\text { direito; demonstrar } \\
\text { probidade e ética; não } \\
\text { ser filiado a partido. }\end{array}$ \\
\hline Guatemala & $\begin{array}{c}\text { Sim Corte } \\
\text { Constitucional. }\end{array}$ & $\begin{array}{l}\text { - } 1 \text { Congresso } \\
\text { Nacional; } \\
\text { - } 1 \text { membro do } \\
\text { Tribunal } \\
\text { Supremo; } \\
\text { - } 1 \text { Presidente } \\
\text { da República; } \\
\text { - } 1 \text { pela } \\
\text { Universidade de } \\
\text { San Carlos, } \\
\text { - 1 Ordem dos } \\
\text { Advogados }\end{array}$ & $\begin{array}{l}5 \text { anos Obs.: } \\
\text { alternam a } \\
\text { presidência, } \\
\text { cada um } 1 \\
\text { ano. }\end{array}$ & Não & $\begin{array}{l}\text { Advogado, boa } \\
\text { reputaçáo, ao menos } 5 \\
\text { anos de formado. }\end{array}$ \\
\hline Haiti & $\begin{array}{l}\text { Não, Suprema } \\
\text { Corte (Cour de } \\
\text { Cassation). }\end{array}$ & $\begin{array}{l}\text { - Indicados pelo } \\
\text { Senado, } \\
\text { aprovados pelo } \\
\text { Presidente }\end{array}$ & $\begin{array}{l}-10 \text { anos ou } \\
\text { vitalício } \\
\text {-contradição } \\
\text { entre arts. } \\
174 \text { e } 177\end{array}$ & Não & $\begin{array}{l}\text { Escola de Magistratura } \\
\text { (lei específica regula). }\end{array}$ \\
\hline Honduras & $\begin{array}{c}\text { Sim, Corte } \\
\text { Constitucional. }\end{array}$ & $\begin{array}{l}\text { Congresso } \\
\text { Nacional } \\
\text { - de uma lista } \\
\text { oferecida por } \\
\text { órgáos do } \\
\text { governo e } \\
\text { ONGs }\end{array}$ & 7 anos & Sim & $\begin{array}{l}\text { Juiz por } 5 \text { anos ou } \\
\text { advogado por } 10 \text { anos. }\end{array}$ \\
\hline México & $\begin{array}{l}\text { Náo, Suprema } \\
\text { Corte de Justiça. }\end{array}$ & $\begin{array}{c}\text { Nomeado pelo } \\
\text { presidente e } \\
\text { aprovado pelo } \\
\text { Senado. }\end{array}$ & 15 anos & Não & $\begin{array}{l}\text { Formado em direito } 10 \\
\text { anos, boa reputaçáo, ter } \\
\text { residido no país ao } \\
\text { menos } 2 \text { anos. }\end{array}$ \\
\hline Nicarágua & $\begin{array}{l}\text { Não, Suprema } \\
\text { Corte de Justiça. }\end{array}$ & $\begin{array}{l}\text { Congresso } \\
\text { Nacional }\end{array}$ & 5 anos & Não & $\begin{array}{l}\text { Juiz por } 5 \text { anos ou } \\
\text { advogado por } 10 \text { anos e } \\
\text { boa reputação. }\end{array}$ \\
\hline Panamá & $\begin{array}{c}\text { Não, Suprema } \\
\text { Corte de Justiça. }\end{array}$ & Presidente & 10 anos & Não & $\begin{array}{l}10 \text { anos como } \\
\text { advogado, professor de } \\
\text { direito ou funcionário } \\
\text { público (prática } \\
\text { jurídica). }\end{array}$ \\
\hline
\end{tabular}




\begin{tabular}{|c|c|c|c|c|c|}
\hline Paraguai & $\begin{array}{l}\text { Não, Suprema } \\
\text { Corte de Justiça. }\end{array}$ & $\begin{array}{l}\text { Indicados por } \\
\text { conselho da } \\
\text { magistratura, } \\
\text { aprovados pelo } \\
\text { Senado e pelo } \\
\text { Presidente }\end{array}$ & Vitalício & & $\begin{array}{c}\text { Doutorado em direito, } \\
10 \text { anos advogado, juiz } \\
\text { ou professor } \\
\text { universitário. }\end{array}$ \\
\hline Peru & $\begin{array}{l}\text { Não, Suprema } \\
\text { Corte de Justiça. }\end{array}$ & $\begin{array}{l}\text { Indicados por } \\
\text { conselho da } \\
\text { magistratura, } \\
\text { aprovados pelo } \\
\text { Congresso e } \\
\text { pelo Presidente }\end{array}$ & 5 anos & Não & $\begin{array}{l}\text { Juiz por } 10 \text { anos ou } \\
\text { advogado por } 15 \text { anos. }\end{array}$ \\
\hline $\begin{array}{c}\text { República } \\
\text { Dominicana }\end{array}$ & $\begin{array}{c}\text { Sim, Corte } \\
\text { Constitucional. }\end{array}$ & $\begin{array}{l}\text { Indicados pelo } \\
\text { Conselho do } \\
\text { Judiciário } \\
\text { (Presidente, } \\
\text { líderes das casas } \\
\text { legislativas, do } \\
\text { Supremo } \\
\text { Tribunal e } \\
\text { membro de } \\
\text { partido não } \\
\text { representado). }\end{array}$ & 9 anos & Não & $\begin{array}{l}\text { Formado em direito, } \\
12 \text { anos advogado, } \\
\text { docente, juiz ou } \\
\text { membro do ministério } \\
\text { público. }\end{array}$ \\
\hline Uruguai & $\begin{array}{l}\text { Não, Suprema } \\
\text { Corte de Justiça. }\end{array}$ & $\begin{array}{l}\text { Indicados pelo } \\
\text { Presidente, } \\
\text { aprovados pelo } \\
\text { Congresso } \\
\text { Nacional }\end{array}$ & 10 anos & $\begin{array}{c}\text { Sim, mas } \\
\text { depois de um } \\
\text { intervalo de } 5 \\
\text { anos }\end{array}$ & $\begin{array}{l}10 \text { anos advogado ou } 8 \\
\text { anos magistrado ou } \\
\text { membro do ministério } \\
\text { público. }\end{array}$ \\
\hline Venezuela & $\begin{array}{c}\text { Não, Supremo } \\
\text { Tribunal de } \\
\text { Justiça. }\end{array}$ & $\begin{array}{l}\text { Indicados pelo } \\
\text { Comitê de } \\
\text { Postulação } \\
\text { Judicial e } \\
\text { aprovados pelo } \\
\text { Congresso } \\
\text { Nacional. }\end{array}$ & 12 anos & Não & $\begin{array}{l}\text { Honra, boa reputação, } \\
15 \text { anos advogado e } \\
\text { pós-graduação, } \\
\text { professor ou juiz. }\end{array}$ \\
\hline
\end{tabular}

Fonte: Os autores, com base nas constituiçóes e leis orgânicas da magistratura.

Todos os casos apresentam o critério cooperativo ou o representativo. Sendo a Bolívia $^{3}$ o único a se utilizar do sufrágio universal. Observamos que uma lista de précandidatos é aprovada pela Assembleia Legislativa e posteriormente as eleições são organizadas em cada estado. Recentemente a Corte Suprema da Argentina declarou a

${ }^{3} \mathrm{O}$ sufrágio universal foi adotado na reforma constitucional de 2009. 
inconstitucionalidade da Reforma Judicial proposta pelo governo de Cristina Kirchner que pretendia adotar este método ${ }^{4}$.

As críticas a essa forma de seleção afirmam que submeteria a suprema corte ao poder político dos partidos e da maioria governamental e dessa forma violaria a separação dos poderes, com sérias consequências para a imparcialidade e a independência judiciais. Além do mais, haveria prejuízo para uma das funçóes das cortes constitucionais de exercer um contraponto à regra do winner takes all, onde as eleiçôes são um tudo ou nada do jogo político (FEREJOHN e PASQUINO, 2004).

Entretanto, observamos que em 13 dos casos há interferência direta do presidente em pelo menos uma das fases do processo seletivo ou em uma parcela dos membros escolhidos, conforme o Quadro 4. Apenas em um caso extremo a escolha fica unicamente nas mãos do chefe do executivo, no Panamá.

Este perfil se alinha com a ideia de que os presidentes querem maximizar sua influência na corte, tanto com o escopo de controlar a revisão judicial quanto de exercer controle indireto nas cortes de primeira instância, porque logicamente é mais fácil lidar com um perfil de juízes que tenham sido escolhidos a dedo por ele ou por seu partido do que pela oposição. Dependendo da configuração institucional, é possível que os presidentes escolham os candidatos e que eles sejam aprovados pela assembleia.

No entanto, embora não haja interferência explícita do executivo na indicação, há a possibilidade de que os presidentes instruam seus aliados do legislativo a nomear os seus favoritos ou negociar "cotas" de juízes com a oposição no congresso (PÉREZ-LIÑÁN e CASTAGNOLA, 2009).

Os mesmos autores concluem que há um interesse, portanto, em disponibilizar vagas nas cortes. Haveria incentivos para que os magistrados se aposentassem, quando a destituição não fosse feita de forma mais direta, como um impeachment (diante dos custos sociais de tomar uma medida arbitrária). As constituiçóes foram unânimes em prover estabilidade aos cargos, sendo a destituição sempre ligada a causas de mau comportamento ou corrupção. Ressaltamos que a subjetividade das causas de perda do mandato disposta nas constituiçóes de todos os casos em análise parecem deixar espaço para manobras de rotatividade dos membros. Também enfatizamos a dificuldade em mensurar a correlação, uma vez que o fim do mandato muitas vezes ocorre simplesmente por aposentadoria voluntária.

\footnotetext{
${ }^{4} \mathrm{O}$ jornal El País interpretou a atitude como um freio "en seco" ao que seria "uno de los asaltos más flagrantes a la separación de poderes que se recuerdan en una democracia homologada”. "Separación de Poderes: El Supremo argentino frena el intento del Gobierno de socavar la independencia judicial”, El País, editorial de 23 de junho de 2013.
} 
As condições mencionadas sinalizam um indesejável espaço para influência do executivo em eventual mudança de mandato, uma vez que não há clareza nas disposições constitucionais quanto aos requisitos para destituição. Perez Liñan e Castagnola (2009) concluem que há influência forte do papel dos executivos em manter uma "corte leal", não raro mudanças na composição das cortes acompanharem alteraçóes partidárias.

Quadro 4 - Indicação dos Magistrados

\begin{tabular}{|c|c|c|c|c|c|c|c|c|c|}
\hline \multicolumn{8}{|c|}{ Interferência do Presidente } \\
\hline Fase & ARG & BRA & HAI & HON & MEX & PAR & PER & REP & URU \\
\hline Número de membros & GUA & COL & CHI & & & & & & \\
\hline Monopólio & PAN & & & & & & & & \\
\hline Ausência & NIC & EQU & ELS & COS & BOL & VEN & & & \\
\hline
\end{tabular}

Fonte: Os autores, com base nas constituiçóes e leis orgânicas da magistratura.

Quanto ao grau de interferência na nomeação dos membros, cujas regras são explicitamente dispostas nas constituiçóes, é possível concluir que será maior a interferência do executivo quanto maior for seu poder de escolha. O Quadro 4 demonstra que, em ao menos uma das fases de indicação, o presidente tem participação direta na maioria dos casos, as demais fases são decididas pelo legislativo ou por sufrágio. Em três casos (Guatemala, Colômbia e Chile) o Presidente pode escolher sozinho determinada quantidade de magistrados. No Panamá, o Presidente detém monopólio na indicação; por fim, na última linha, há total ausência de sua participação em quaisquer fases.

Atento a outro fator que poderia também pesar para além das causas de perda do cargo, Ríos-Figueroa (2007) analisa a duração do mandato. Se o mandato do juiz fosse mais longo do que o de quem o indicou, os riscos de dependência diminuiriam, portanto seria ideal que o mandato do magistrado fosse mais longo do que o da a autoridade que o nomeou.

Mantendo as demais variáveis constantes, quanto maior a duração do mandato, maior imparcialidade terá o juiz para decidir, por ficar mais livre de pressôes políticas. Assim sendo, em tese seria ideal que os mandatos fossem sempre vitalícios. Por sua vez, a possibilidade de recondução em mandatos limitados pode influenciar na dependência, pois acaba se tornando uma forma de recompensa para magistrados "fiéis".

Ocorre que nem sempre um mandato vitalício é mais longo do que aquele de termo definido, em todos os casos (Argentina, Brasil e Paraguai) em que a duração é vitalícia a aposentadoria compulsória se dá aos 75 (setenta e cinco) anos de idade e 
por isso pode ocorrer de a duração acabar sendo menor do que um mandato com duração de 15 (quinze) anos, como no caso do México.

Talvez uma fórmula para medir o grau de independência com base no perfil dos magistrados escolhidos seja interessante. Ríos-Figueroa e Navia (2005) apresentam uma função entre autoridades que nomeiam e destituem os membros das cortes e duração do mandato. Apesar de não haver fontes confiáveis de como ocorrem as manobras políticas relacionadas a aposentadoria e renúncia, que possivelmente poderiam influenciar nos resultados, é realmente impactante o critério de escolha e permanência dos membros no grau de independência, sobretudo diante do fato de estarem dispostos na constituição.

Pérez-Liñán e Castagnola (2009) contabilizaram os magistrados que eram nomeados como membros das cortes a cada ano em 11 países (Argentina, Brasil, Chile, Colombia, Costa Rica, El Salvador, Guatemala, Honduras, México, Panamá e Uruguai) de 1904 a 2006; aferindo a frequência com que as mudanças ocorriam e, em alguns casos, o ciclo era influenciado pela chegada de novo presidente ao poder.

The analysis of conditional coefficients shows that, between 1904 and 1944, the effect of new administrations on the appointment of new justices was virtually indistinguishable from zero; between 1945 and 1977 , every government change increased the appointment of justices by 26 percent (significant at the .05 level), and between 1978 and 2006, new administrations in-creased the number of appointments by 34 percent (significant at the .01 level) (PÉREZ-LIÑÁN e CASTAGNOLA, 2009, p. 106) 5 .

O período de 1978 a 2006 - que cobre a primeira publicação utilizada na revisão de literatura e o momento atual - apresentou uma maior correlação entre a nomeação de juízes e novas eleiçóes, fato que o autor atribuiu ao importante papel de veto players dos tribunais constitucionais e à judicialização da política, o que ocasionou uma maior corrida em busca do controle. Dessa forma, concluímos que, aparentemente, a terceira onda de democratização implicou uma tendência de maior controle sobre o processo de nomeação, sobretudo as cortes constitucionais.

\footnotetext{
${ }^{5} \mathrm{O}$ resultado indica que os realinhamentos executivos tiveram consequências políticas mais brandas para o supremo tribunal no início do século XX do que mais tarde. A análise dos coeficientes mostra que, entre 1904 e 1944, o efeito das novas administraçóes sobre a nomeação de novos juízes era virtualmente indistinguível de zero; entre 1945 e 1977, cada mudança de governo aumentou a nomeação de juízes por 26 por cento e entre 1978 e 2006, a nova administração aumentou o número de indicaçóes em 34 por cento (tradução dos autores).
} 


\section{Tipos de controle: difuso e/ou concentrado e acesso às cortes}

Os magistrados das cortes constitucionais possuem uma posição muito privilegiada dentro do judiciário, pois podem declarar nulo qualquer lei ou ato do governo que contrarie a constituição.

Tal fato concedeu ao judiciário um protagonismo na proteção dos direitos individuais contra o Estado, todas as constituiçôes apresentam traços dessa característica e há várias ações constitucionais à disposição de qualquer cidadão que tenha seus direitos fundamentais violados.

Por outro lado, também lhe concede poder de veto player e isso tanto pode significar necessidade de tomada de decisão em assuntos polêmicos sobre os quais os políticos prefeririam não se posicionar (por conta de impactos nas eleiçóes, por exemplo), como pode significar a possibilidade de coligações entre as cortes e interesses partidários ou de classes específicas. É algo que se deseja naturalmente evitar, pois seria uma influência negativa à imparcialidade e, consequentemente, à independência.

Portanto, o controle de constitucionalidade apresenta amplas variações, sobretudo quando se dirige a uma norma em abstrato ${ }^{6}$, aparecendo limitado em alguns casos a alguns órgãos jurisdicionais ou permitem apenas que poucos possam figurar como titulares da ação de inconstitucionalidade. Por outro lado, alguns casos apresentam maior abertura em relação aos legitimados. Com relação aos órgãos jurisdicionais que exercem o controle, podem ser todos os juízes de qualquer instância (difuso) ou pode ser apenas a cargo de um tribunal específico (concentrado).

No tocante aos efeitos do controle de constitucionalidade, podem anular a norma em sua origem, declarando-a inconstitucional, o que irá atingir a todos os indivíduos mesmo que não figurem no processo como titulares (contra todos ou orga omnes) ou, podem proteger apenas as partes que moveram a ação contra os efeitos da inconstitucionalidade (inter partes). Importante diferenciá-los, pois podem determinar qual o alcance das decisões proferidas e certamente pesam na amplitude do poder das cortes.

Quanto à aplicabilidade temporal de suas decisóes, tanto pode ser ex nunc (não retroativa) quanto ex tunc (retroativa até a data do fato), há também a possibilidade de modular os efeitos, como no caso brasileiro - ao mesmo tempo em

\footnotetext{
${ }^{6}$ Norma em abstrato significa que inexiste uma relação jurídica concreta configurando que o titular da ação tenha sido efetivamente prejudicado pela suposta inconstitucionalidade. Quando há prejuízos para o titular da ação, diz-se que o controle é concreto.
} 
que promulga a decisão, o tribunal determina a partir de que momento os efeitos irão valer.

As formas de controle encontradas nos casos podem significar muito sobre o poder concedido às suas decisóes e é uma interessante forma de mensurar sua força, porque é um dos casos em que poucas variáveis influenciarão nos efeitos "reais" em contraposição aos efeitos descritos nas constituiçôes, já que esses mecanismos são obedecidos rigorosamente pelos magistrados, em respeito à segurança jurídica.

Percebemos nitidamente a simbiose entre um modelo constitucional norteamericano, que responde a sistema common law e tradição jurídica apoiada por uma sistema civil law $w^{7}$ gerada a partir da incorporação de instrumentos processuais de ambos os modelos, apresentando muitas peculiaridades e diversas combinaçóes possíveis dentre as formas de controle de constitucionalidade, as quais exploramos no Quadro 5.

Quadro 5-Espécies de controle de constitucionalidade

\begin{tabular}{|c|c|}
\hline Concreto & Indivíduo ou grupo ofendido diretamente por violaçáo à norma constitucional \\
\hline Abstrato & Não há ofensa direta, apenas denúncia de que norma existente é contrária à constituição \\
\hline Concentrado & Centralizado em um único tribunal \\
\hline Difuso & Possibilidade de controle por qualquer juiz ou tribunal \\
\hline Contra todos & Os efeitos atingem a coletividade \\
\hline Inter partes & Os efeitos atingem apenas os ofendidos, titulares da açáo \\
\hline Ex nunc & Não retroage, efeitos a partir da promulgação da sentenı \\
\hline Ex tunc & Efeitos alcançam fatos anteriores, tornando a norma nula desde seu nascimento \\
\hline Modulaçáo & Possibilidade de determinar a partir de que momento a decisão será aplicável \\
\hline
\end{tabular}

Fonte: Os autores.

Deduzimos que o controle abstrato garante à decisão judicial um efeito muito amplo, equiparado à função de legislar; enquanto que o concreto parece atender ao papel de protetor de direitos individuais tradicionalmente atribuído ao judiciário, sobretudo nos momentos de turbulências políticas (sem entrarmos no mérito da efetividade da proteção).

\footnotetext{
${ }^{7}$ Para um aprofundamento neste hibridismo que se caracteriza por toda América Latina vide: Carvalho (2010).
} 
Por sua vez, o controle concentrado transfere considerável poder aos tribunais constitucionais, que ficariam com o monopólio das decisões dessa natureza; o difuso possui a vantagem de ampliar o acesso à maior quantidade de indivíduos possível, mas parece descentralizar e diminuir a influência das cortes constitucionais.

Quanto aos efeitos, decisóes que atingem a coletividade obviamente significam maior poder para a corte; enquanto decisôes inter partes se assemelham às condições elucidadas sobre as normas em concreto.

Finalmente, quanto à temporização dos efeitos ex tunc, também se equiparam a quase legislar, ao passo que o efeito inter partes condiz com os objetivos dos remédios constitucionais de conceder proteção aqueles que recorrem às cortes. A modulação de efeitos parece propiciar o maior grau de liberdade de ambos, porque permite que a corte tenha o poder de definir a partir de quando sua decisão será aplicável.

Em resumo, o controle abstrato e com acesso restrito parece mais apropriado para servir como canalização de demandas políticas, mas é ineficaz para garantir direitos individuais; por sua vez, o controle concreto e com efeito inter partes é mais adequado para proteger os direitos individuais. Finalmente, o controle de constitucionalidade concentrado e abstrato é o mais político dos instrumentos processuais existentes.

A literatura neoinstitucional da ciência política que aborda o tema da judicialização tomou a revisão abstracta da legislação como foco do debate empírico e aponta o desenho institucional como elemento potenciador da judicialização (CARVALHO, 2009, p. 316).

Tendo os conceitos em mente e a valoração que podem simbolizar em possíveis mensuraçôes dos poderes dados pelo desenho constitucional, o Quadro 6 detalha quem está habilitado a oferecer as demandas e qual o alcance do controle constitucional em cada corte.

Quadro 6 - Acesso às cortes, tipo de controle e efeitos da declaração

\begin{tabular}{|c|c|c|}
\hline Corte Constitucional & $\begin{array}{c}\text { Legitimados para propor açáo de } \\
\text { inconstitucionalidade abstrata }\end{array}$ & $\begin{array}{c}\text { Tipo de Controle e Efeitos da } \\
\text { Declaraçáo }\end{array}$ \\
\hline Argentina & $\begin{array}{c}\text { Náo há, o controle é totalmente } \\
\text { concreto. }\end{array}$ & $\begin{array}{c}\text { Difuso e inter partes, quando exercido } \\
\text { pela suprema corte (como recursal), pode } \\
\text { ser } \text { erga omnes. }\end{array}$ \\
\hline Bolívia & $\begin{array}{c}\text { Presidente, membro da Assembleia } \\
\text { Legislativa, Máxima autoridade dos }\end{array}$ & $\begin{array}{c}\text { Concentrado apenas, inter partes ou erga } \\
\text { omnes; concreto ou abstrato; ex nunc; }\end{array}$ \\
\hline
\end{tabular}




\begin{tabular}{|c|c|c|}
\hline & territorios e defensor publico. & Efeito vinculante. \\
\hline Brasil & $\begin{array}{c}\text { Presidente da República; } \\
\text { Mesa do Senado Federal, da Câmara } \\
\text { dos Deputados, da Assembleia } \\
\text { Legislativa; o Governador de Estado } \\
\text { ou DF; } \\
\text { o Governador de Estado ou do } \\
\text { Distrito Federal; Procurador-Geral } \\
\text { da República; Conselho Federal da } \\
\text { OAB; Partido Político com } \\
\text { representação no Congresso } \\
\text { Nacional;confederação sindical ou } \\
\text { entidade de classe de âmbito } \\
\text { nacional. }\end{array}$ & $\begin{array}{l}\text { Concentrado e difuso; concreto e } \\
\text { abstrato; possibilidade de modulaçáo } \\
\text { temporal. }\end{array}$ \\
\hline Chile & $\begin{array}{l}\text { Presidente da República, do Senado } \\
\text { ou da Câmara, } 1 \backslash 4 \text { dos membros de } \\
1 \text { das casas; ação popular. }\end{array}$ & $\begin{array}{l}\text { Concentrado e difuso; concreto e } \\
\text { abstrato. }\end{array}$ \\
\hline Colombia & $\begin{array}{l}\text { Presidente, membro da Assembleia } \\
\text { Legislativa e Maxima autoridade dos } \\
\text { territorios autônomos. }\end{array}$ & $\begin{array}{l}\text { Concentrado e difuso; concreto e } \\
\text { abstrato; possibilidade de modulaçáo } \\
\text { temporal. }\end{array}$ \\
\hline Costa Rica & $\begin{array}{l}\text { Qualquer pessoa, sociedade ou } \\
\text { associação. }\end{array}$ & $\begin{array}{l}\text { Concentrado e difuso; concreto e } \\
\text { abstrato; erga omnes e inter partes. }\end{array}$ \\
\hline El Salvador & $\begin{array}{l}\text { Qualquer pessoa ou o Ministério } \\
\text { Público. }\end{array}$ & $\begin{array}{l}\text { Concentrado e abstrato; difuso e } \\
\text { concreto. }\end{array}$ \\
\hline Equador & Qualquer cidadão. & $\begin{array}{l}\text { Apenas em } 2008 \text { passou a exercer } \\
\text { jurisdição - inter partes e concentrado. }\end{array}$ \\
\hline Guatemala & Qualquer cidadão. & $\begin{array}{c}\text { Abstrato e concreto; inter partes e erga } \\
\text { omnes; efeito ex nunc. }\end{array}$ \\
\hline Haiti & Qualquer cidadão. & Inter partes e efeitos ex nunc. \\
\hline Honduras & Qualquer cidadão. & Erga omnes; ex tunc. \\
\hline México & Apenas órgãos do governo. & $\begin{array}{l}\text { Concentrado e difuso; concreto e } \\
\text { abstrato; possibilidade de modulação } \\
\text { temporal. }\end{array}$ \\
\hline Nicarágua & Qualquer cidadão & $\begin{array}{l}\text { Abstrato e concreto; inter partes e erga } \\
\text { omnes; efeito ex nunc. }\end{array}$ \\
\hline Panamá & Qualquer cidadão & Concentrado e erga omnes \\
\hline Paraguai & Qualquer cidadão & $\begin{array}{l}\text { Concentrado; inter partes ou erga omnes; } \\
\text { ex nunc. }\end{array}$ \\
\hline
\end{tabular}




\begin{tabular}{|c|c|c|}
\hline Peru & $\begin{array}{c}\text { Presidente, Procurador-Geral, } \\
\text { Defensor del pueblo. }\end{array}$ & $\begin{array}{c}\text { Difuso e concentrado; erga omnes e inter } \\
\text { partes; } \text { ex nunc. }\end{array}$ \\
\hline República Dominicana & Qualquer cidadão. & $\begin{array}{c}\text { Difuso e concentrado; erga omnes e inter } \\
\text { partes; ex nunc. }\end{array}$ \\
\hline Uruguai & $\begin{array}{c}\text { Não há ADIN, o controle é } \\
\text { totalmente concreto. Assembleia } \\
\text { toma conhecimento da sentença e } \\
\text { decide se exclui a norma ou não. }\end{array}$ & Concentrado, inter partes e ex nunc. \\
\hline Venezuela & $\begin{array}{c}\text { De ofício ou como tribunal de } \\
\text { recurso ao controle difuso, dando } \\
\text { efeito vinculante. }\end{array}$ & $\begin{array}{c}\text { Difuso e concentrado; erga omnes e inter } \\
\text { partes; ex nunc. }\end{array}$ \\
\hline
\end{tabular}

Fonte: Os autores.

$\mathrm{O}$ que podemos concluir a partir desta acumulação assistemática de mecanismos processuais é que ela reflete, de um lado, a possível ineficiência sistema difuso (a partir dos anos cinquenta do século XX a tendência tem sido concentrar o controle de constitucionalidade) e, por outro lado, a necessidade de resolver a obrigação de dar coerência ao sistema. Em 2004 no Brasil, por exemplo, a emenda n. 45 deixou muitas opiniôes divididas quanto à súmula vinculante do STF, muitos juízes entenderam como uma afronta ao seu livre convencimento - exatamente por conta da tradição civil law. 
Quadro 7 - Efeitos e Acesso aos instrumentos de controle de constitucionalidade de 2013

\begin{tabular}{|c|c|c|c|c|}
\hline & \multicolumn{2}{|l|}{ Efeitos } & \multicolumn{2}{|c|}{ Acesso } \\
\hline Tipo de Instrumento & Erga Omnes & Inter Partes & Aberto & Restrito \\
\hline Concreto; Centralizado & $\begin{array}{c}\text { Honduras } \\
\text { Bolívia } \\
\text { México }\end{array}$ & $\begin{array}{c}\text { Brasil } \\
\text { Chile } \\
\text { Costa Rica } \\
\text { Rep. Dominicana } \\
\text { El Salvador } \\
\text { Guatemala } \\
\text { Panamá } \\
\text { Paraguai } \\
\text { Peru } \\
\text { Uruguai } \\
\text { Venezuela }\end{array}$ & $\begin{array}{c}\text { Brasil } \\
\text { Costa Rica } \\
\text { El Salvador } \\
\text { Guatemala } \\
\text { Honduras } \\
\text { Panamá } \\
\text { Paraguai }\end{array}$ & $\begin{array}{c}\text { Bolívia } \\
\text { Chile } \\
\text { Equador } \\
\text { México } \\
\text { Peru } \\
\text { Uruguai } \\
\text { Venezuela }\end{array}$ \\
\hline Concreto; Descentralizado & Nenhum & $\begin{array}{c}\text { Argentina } \\
\text { Bolívia } \\
\text { Brasil } \\
\text { Colômbia } \\
\text { Equador } \\
\text { El Salvador } \\
\text { Guatemala } \\
\text { Honduras } \\
\text { México } \\
\text { Panamá } \\
\text { Peru } \\
\text { Venezuela }\end{array}$ & $\begin{array}{c}\text { Argentina } \\
\text { Bolívia } \\
\text { Brasil } \\
\text { Colômbia } \\
\text { Equador } \\
\text { El Salvador } \\
\text { Guatemala } \\
\text { Honduras } \\
\text { México } \\
\text { Panamá } \\
\text { Peru } \\
\text { Venezuela }\end{array}$ & Nenhum \\
\hline
\end{tabular}

Fonte: Os autores.

Consideramos, portanto, que a judicialização da política estaria mais atrelada à possibilidade de modificar a lei em abstrato e com efeito erga omnes, tendo em vista a equiparação à lei de que a decisão judicial se reveste, pois obriga a todos e apresenta a anterioridade. Ocorre que as pesquisas parecem não ter atentado para esta sutileza, jogando todos os tribunais constitucionais no mesmo grupo dos que teriam poder para "fazer política".

É certo que decidir parcialmente em benefício de uma minoria e indo de encontro ao que a constituição de fato quer dizer poderia ser considerada uma forma de fazer a política (policy making), entretanto, há de se convir que existe uma clara diferença entre "legislar" e "julgar".

O controle de constitucionalidade difuso em um país civil law não vai dar o condão de legislar, pelo simples fato de que em sua tradição jurídica a lei é 
hierarquicamente superior à jurisprudência, de forma que uma decisão inter partes no máximo iria conseguir criar um precedente para novas açóes análogas, o que levaria tempo considerável para que as reiteradas decisões contrárias a determinada lei se consolidassem e tornassem tal norma sem efeitos.

Por essas razões, não podemos considerar a declaração de inconstitucionalidade com efeitos inter partes como um ato de legislar, especialmente em contextos onde não há o controle concentrado, como na Argentina.

Finalmente, imaginamos que os aspectos mencionados podem significar excelentes termômetros para aferir o poder concedido às cortes constitucionais e como se aproximam do ideal de independência, sendo a independência relacionada a operar com imparcialidade e em respeito ao rule of law.

\section{Considerações Finais}

O presente estudo buscou trazer à discussão como se encontram as feiçôes institucionais dispostas ao longo da América Latina no tocante à disposição de suas cortes constitucionais e em como tais desenhos podem ser determinantes ao criar condiçôes favoráveis à sua independência.

Resgatamos abordagens neoinstitucionalistas por acreditarmos que o desenho constitucional tem grande influência nos resultados políticos futuros, ao passo que também nos dizem muito sobre as condiçóes ambientais nas quais foram criadas.

O espaço reservado para dispor sobre quem exercerá o papel de guarda da constituição, por sua tamanha responsabilidade em assegurar que os compromissos simbolizados na constituição sejam cumpridos, sem dúvida pode ser interpretado como um dos que possuem maior destaque.

A duração do mandato por ser em muitos casos vitalícia permite que quem ocupe o cargo se mantenha no poder por algumas geraçóes e no âmbito legislativo, o tempo é potencializado por conta das constantes mudanças e novas leis promulgadas.

- Rebecca Magalhães é Doutoranda em Ciência Política pela Universidade Federal de Pernambuco (UFPE). E-mail: magalhaes.rebecca@gmail.com.

- Ernani Carvalho é Professor do Departamento de Ciência Politica da UFPE e Pesquisador do CNPq. Doutor em Ciência Política pela Universidade de São Paulo (USP). E-mail: ernanicarvalho@gmail.com. 


\section{Referências}

CARVALHO, Ernani. Trajetória da revisão judicial no desenho constitucional brasileiro: tutela, autonomia e judicialização. Sociologias, Porto Alegre, n. 23, p. 176-207, jan.-abr. 2010. Judicialização da política no Brasil: controlo de constitucionalidade e racionalidade política. Análise Sociaı, Lisboa, v. XLIV, n. 191, p. 315-335, 2009.

ELKINS, Zachary; GINSBURG, Tom; MELTON, James. The Endurance of National Constitutions. New York: Cambridge University Press, 2009.

FEREJOHN, John; PASQUINO, Pasquale. Constitutional Adjudication: Lessons from Europe. Texas Law Review, Austin, EUA, n. 82, p. 1671-1704, 2004.

GINSBURG, Tom. Judicial Review in New Democracies. Constitutional Courts in Asian Cases. New York: Cambridge University Press, 2003.

HAYO, Bernd; VOIGT, Stefan. Explaining de Facto Judicial Independence. International Review of Law and Economics, v. 27, n. 3, p. 269-290, set. 2007.

PÉREZ-LIÑÁN, Aníbal; CASTAGNOLA, Andrea. Presidential Control of High Courts in Latin America: A Long-term View (1904-2006). Journal of Politics in Latin America, Hamburg, Germany, v. 1, n. 2, p. 87-114, 2009.

POZAS-LOYO, Andrea; RÍOS-FIGUEROA, Julio. Enacting constitutionalism: The origins of independent judicial institutions in Latin America. Comparative Politics, New York, v. 42, n. 3, abr. 2010.

RÍOS-FIGUEROA, Julio. Fragmentation of Power and the Emergence of an Effective Judiciary in Mexico, 1994-2002. Latin American Politics \& Society, Miami, v. 49, n. 1, p. 31-57, abr. 2007. The Institutional Setting for Constitutional Justice in Latin America. Toronto: APSA Annual Meeting Paper, 3-6 set. 2009.

RÍOS-FIGUEROA, Julio; NAVIA, Patricio. The Constitutional Adjudication Mosaic of Latin America. Comparative Political Studies, v. 38, n. 2, p. 189-217, mar. 2005.

VERNER, Joel G. The Independence of Supreme Courts in Latin America: a Review of Literature. Journal of Latin American Studies, Cambridge, Inglaterra, v. 16, n. 2, p. 463-506, nov. 1984. 